\title{
Transitivity in the Big Ten
}

\author{
MICHAEL H. BIRNBAUM \\ University of Illinois, Champaign, Illinois
}

\begin{abstract}
Football outcomes are often used to illustrate violations of transitivity because, if team $A$ beats team $B$, and if team $B$ beats team $C$, there is no guarantee that team $C$ will not beat team A. In the Big Ten Conference, every team played every other team in 1983, providing a complete test of transitivity of the football teams. The conference was very nearly transitive in 1983, with only one violation involving adjacent teams with weak records.
\end{abstract}

Transitivity is a key condition in the construction of numerical representations of empirical relationships (Coombs, 1983; Krantz, Luce, Suppes, \& Tversky, 1971). Transitivity alone is not sufficient to yield an ordering, because a given empirical structure may not define the relationship on all pairs. For example, the relation $P=$ "is the ancestor of" is a transitive relationship because, if Adam is the ancestor of Bob and Bob is the ancestor of Carolyn, then Adam is the ancestor of Carolyn. However, Bob's sister, Diane, is not the ancestor of Bob and Bob is not the ancestor of Diane. To describe this state of affairs, we say that these elements are not connected by the $P$ (ancestor) relation. If a structure is connected and transitive, then it can be used to generate an ordinal scale (Krantz et al., 1971).

\section{FINITE WEAK ORDER}

Let $A$ be a set of entities, and let $R$ be an empirical relation. Then, the structure $\langle A, R\rangle$ can be represented by a finite weak order if and only if the following two axioms are satisfied: (1) connected-for all $\mathrm{a}$ and $\mathrm{b}$ in $\mathrm{A}$, either $a R b$ or $b R a$; (2) transitive-for all $a, b$, and $c$ in A, $\mathrm{aRb}$ and $\mathrm{bRc}$ implies $\mathrm{aRc}$.

If these conditions are satisfied, then the empirical structure $\langle A, R\rangle$ can be represented by the numerical structure $\left\langle\operatorname{Re}^{+}, \geqslant\right\rangle$, which assigns numerical ranks to the elements of $A$ such that for all $a$ and $b$ in $A$,

$$
\mathrm{aRb} \text { iff } \mathrm{s}_{\mathrm{a}} \geqslant \mathrm{s}_{\mathrm{b}} .
$$

The scale values, $s_{a}$ and $s_{b}$, are said to constitute an ordinal scale because all other scales, $s^{*}$, that satisfy Expression 1 are monotonically related to $s$. Thus, if $\mathrm{s}^{*}$ also satisfies Expression 1, then for all a in A, $\mathrm{s}^{*}(\mathrm{a})=$ $M[s(a)]$, where $M$ is a monotonic increasing function.

\section{OPERATIONAL DEFINITIONS}

Similar-sounding relations may or may not be transitive, depending on the precise operational definition.

The author's mailing address is: Department of Psychology, University of Illinois, Champaign, IL 61820.
For example, suppose we define the relation "is at least as loud as" on the set of $1000-\mathrm{Hz}$ tones varying in intensity: $\mathrm{aLb}$ if the subject says " $\mathrm{a}$ is at least as loud as b." This relation is unlikely to be transitive, because the subject could easily say the opposite on the next presentation of the same two tones. To avoid the problem of inconsistent judgments from subjects, the ordering relation can be defined stochastically as follows: aLb iff $\mathrm{P}(\mathrm{a}, \mathrm{b}) \geqslant .5$, where $\mathrm{P}(\mathrm{a}, \mathrm{b})$ is the probability that the subject says, "a is at least as loud as b." Note that the observed data will involve a proportion, so this definition involves inferences from observed proportions to underlying probabilities. There will still be problems: For example, if tones $a$ and $b$ are presented sequentially, then subjects will be comparing memories of loudness of tones that have different times in memory. Empirically, if the same tone is presented twice, subjects typically say the second tone was louder than the first, especially if the two tones are fairly intense. However, for weak tones, the second of two equally faint tones is often judged quieter than the first. Order effects can thus lead to violations of transitivity unless the definition of the ordering takes the possibility of order effects into account either through some experimental setup or through a more complete theoretical analysis.

On the other hand, it is possible to select operational definitions so that transitivity becomes almost trivial. For example, let the subject assign a number to the loudness of each tone and define $\mathrm{L}$ as follows: $\mathrm{aLb}$ iff $\mathrm{N}(\mathrm{a}) \geqslant \mathrm{N}(\mathrm{b})$. Obviously, because $\mathrm{N}(\mathrm{a})$ is a number, the numbers will be transitive. However, this trivial transitivity of numbers has no special empirical status in this situation.

The point to remember is that careful operational definition is required. By selection of operational definitions, it would be possible to argue that loudness of $1000-\mathrm{Hz}$ tones varying in intensity does or does not satisfy the requirements of a finite weak order. Coombs (1983) presents a nice discussion of different definitions that lead to a variety of operational specifications of transitivity.

Examples of finite weak orders have been discussed by Coombs (1983), Coombs, Dawes, \& Tversky (1970), and Krantz et al. (1971). Tversky (1969) presented evi- 
dence against transitivity of preferences for gambles. Some examples of transitivity include: (1) the scale of hardness, based on the scratching relation (diamonds are harder than glass because diamonds scratch glass); (2) pecking orders among chickens (if chicken a pecks chicken $b$ and chicken $b$ pecks chicken $c$, then chicken a pecks chicken c); (3) preferences for outcomes varying in one dimension, such as monetary prizes (if $\$ 100$ is preferred to $\$ 10$ and $\$ 10$ is preferred to $\$ 1$, then $\$ 100$ is preferred to $\$ 1$ ). Football outcomes defined on single games are often used to illustrate the concept of transitivity by showing clear violations.

\section{TRANSITIVITY IN THE BIG TEN}

Define the relation "beat or tied" as follows: $\mathrm{aRb}$ if and only if team a got as many points as or more points than team $b$ in the football game between them.

One problem with football is that all teams are not connected. That is, the relation $\mathrm{R}$ is not defined on every pair of teams. In 1983, however, every team in the Big Ten played every other team, so the structure is connected.

To investigate transitivity, a $10 \times 10$ matrix was constructed for the Big Ten as follows: if the column team $(j)$ beat the row team (i), then $X_{i j}=1$; if the column team lost to the row team, then $X_{i j}=0$; if the teams tied, then $X_{i j}=.5$. The rows and columns were then arranged in order of descending values of the column totals. This procedure yields Table 1 , which shows the outcomes of 1983 football games in the Big Ten.

Table 1 shows reasonable agreement with transitivity. If $X_{i j}=1$ and $X_{j k}=1$, then $X_{i k}=1$. Table 1 shows that Illinois beat all nine opponents; Michigan lost to Illinois but beat the other eight teams; Iowa lost to Illinois and Michigan, but beat the other seven schools; Ohio State lost to Illinois, Michigan, and Iowa and beat the other six teams, etc. The only violations involved adjacent teams with weak records: Northwestern beat Indiana, Indiana beat Michigan State, and Michigan State beat Northwestern. Had Michigan State beaten Indiana, there would have been no violations of transitivity, out of 45 games!
Dennis Green, coach of Northwestern (quoted by McDonald, 1983), remarked that there were no upsets in the Big Ten. From the viewpoint of the oddsmakers, however, there were many upsets. Illinois, for example, was predicted to lose to Michigan State, a team that had beaten Notre Dame, to Iowa, which had beaten Penn State, to Wisconsin, which had beaten Missouri, to Ohio State, which had beaten Oklahoma, and to Michigan, which was $5-0$ in the Big Ten. Michigan, Iowa, and Ohio State were nationally rated in the top 10 teams when they met Illinois. Only from the viewpoint of transitivity does Coach Green's remark about upsets seem justified.

It is worth noting that transitivity would have been maintained had Michigan beaten Illinois, or if any other pair of adjacent teams had reversed the outcome. In fact, disregarding ties, there are $n$ ! transitive orders. For example, in the Big Ten, with no ties, there would be 10 ! ways for perfect transitivity to occur. Nevertheless, transitivity is very informative because, with $n$ objects, there are 2 raised to the $(n) \cdot(n-1) / 2$ power ways for the pairwise tests (games) to come out. Thus, in the Big Ten, there are $2^{45}$ ways for the games to come out, disregarding ties, nearly 10 million ways for every transitive way!

It would be interesting to know the extent to which transitivity is satisfied in football. Colleen Surber, of Wisconsin, pointed out that Wisconsin beat the Missouri team that defeated Illinois in their season opener (personal communication, November 19, 1983) Despite the facts that Michigan had beaten Iowa and that Iowa had beaten Ohio State, Clyde Coombs of Michigan expressed considerable interest in finding out the Michigan-Ohio State score (personal communication, November 19, 1983). Thus, football may be nearly transitive and still provide enough exceptions and suspense to make a useful example to teach students the nontriviality of transitivity of empirical relationships.

\section{REFERENCES}

Соовs, C. (1983). Mathematics and psychology. Ann Arbor: University of Michigan Press.

Coombs, C., DAwes, R., \& Tversky, A. (1970). Introduction to mathematical psychology. Englewood Cliffs, NJ: Prentice-Hall.

Table 1

1983 Big Ten Football Records

\begin{tabular}{|c|c|c|c|c|c|c|c|c|c|c|}
\hline \multirow[b]{2}{*}{ Team } & \multicolumn{10}{|c|}{ Team } \\
\hline & $\begin{array}{c}\text { IL } \\
(9-1)\end{array}$ & $\begin{array}{c}\text { UM } \\
(8-1)\end{array}$ & $\begin{array}{c}\mathrm{IO} \\
(7-2)\end{array}$ & $\begin{array}{l}\text { OSU } \\
(6-3)\end{array}$ & $\begin{array}{l}\text { WIS } \\
(5-4)\end{array}$ & $\begin{array}{c}\mathrm{PU} \\
(3-5-1)\end{array}$ & $\begin{array}{c}\text { MSU } \\
(2-6-1)\end{array}$ & $\begin{array}{l}\text { IND } \\
(2-7)\end{array}$ & $\begin{array}{l}\mathrm{NU} \\
(2-7)\end{array}$ & $\begin{array}{l}\text { MINN } \\
(0-9)\end{array}$ \\
\hline Illinois (IL) & $x$ & 0 & 0 & 0 & 0 & 0 & 0 & 0 & 0 & 0 \\
\hline Michigan (UM) & 1 & $x$ & 0 & 0 & 0 & 0 & 0 & 0 & 0 & 0 \\
\hline Iowa (IO) & 1 & 1 & $x$ & 0 & 0 & 0 & 0 & 0 & 0 & 0 \\
\hline Ohio State (OSU) & 1 & 1 & 1 & $x$ & 0 & 0 & 0 & 0 & 0 & 0 \\
\hline Wisconsin (WIS) & 1 & 1 & 1 & 1 & $x$ & 0 & 0 & 0 & 0 & 0 \\
\hline Purdue (PU) & 1 & 1 & 1 & 1 & 1 & $x$ & $1 / 2$ & 0 & 0 & 0 \\
\hline Michigan State (MSU) & 1 & 1 & 1 & 1 & 1 & $1 / 2$ & $x$ & 1 & 0 & 0 \\
\hline Indiana (IND) & 1 & 1 & 1 & 1 & 1 & 1 & 0 & $x$ & 1 & 0 \\
\hline Northwestern (NU) & 1 & 1 & 1 & 1 & 1 & 1 & 1 & 0 & $x$ & 0 \\
\hline Minnesota (MINN) & 1 & 1 & 1 & 1 & 1 & 1 & 1 & 1 & 1 & $x$ \\
\hline
\end{tabular}

Note $-1=$ column team beat row team; $\mathrm{x}=$ team with itself; $0=$ column team lost to row team; $1 / 2=$ tie. 
Krantz, D. H., Luce, R. D., Suppes, P., \& Tversky, A. Tversky, A. (1969). Intransitivity of preference. Psychological (1971). Foundations of measurement. New York: Academic Press.

Review, 76, 31-48.

McDonald, J. (1983, November 20). NU coach Green: No upsets in Big Ten season. The Champaign-Urbana News Gazette, p. E-2.

(Manuscript received for publication March 19, 1984.) 